\title{
Mechanisms and Treatment of Resistant Hypertension
}

\author{
Eduardo Pimenta, David A. Calhoun, Suzanne Oparil \\ Department of Hypertension and Nephrology, Instituto Dante Pazzanese de Cardiologia, Vascular Biology and Hypertension Program, University of \\ Alabama at Birmingham - São Paulo, SP - Brazil - Birmingham, AL - USA
}

\section{Definition and prevalence}

Resistant hypertension is defined as blood pressure (BP) that remains above goal in spite of use of three antihypertensive medications in effective doses, usually including a diuretic ${ }^{1}$. Patients who are intolerant of diuretics and have uncontrolled $\mathrm{BP}$ on regimens of 3 drugs from other classes are also considered to have resistant hypertension. The BP goal is $<140 / 90 \mathrm{~mm} \mathrm{Hg}$ in the general population of hypertensives and $<130 / 80 \mathrm{~mm} \mathrm{Hg}$ in hypertensive patients with diabetes or chronic kidney disease (CKD) (glomerular filtration rate $<60 \mathrm{ml} / \mathrm{min} / 1.73 \mathrm{~m}^{2}$; serum creatinine $>1.5 \mathrm{mg} / \mathrm{dl}$ in men or $>1.3 \mathrm{mg} / \mathrm{dl}$ in women; albuminuria $>300 \mathrm{mg} / 24-\mathrm{hr}$ or $>200 \mathrm{mg} / \mathrm{g}$ creatinine) $)^{1}$. Similarly, patients who require 4 or more medications to control their BP are considered to have resistant hypertension.

Factors that predispose to antihypertensive treatment resistance include population characteristics, such as increased life expectancy, higher obesity rates and decreased physical activity, as well as provider characteristics, including inadequate attention to systolic BP (SBP) elevations and the more aggressive BP goals recommended by recent guidelines. The various contributing factors (Table 1) and secondary causes related to resistant hypertension (Table 2 ) are discussed in this review.

\section{Pseudoresistance}

Pseudoresistance is the appearance of lack of BP control caused by inaccurate measurement of BP, inappropriate drug choices/doses, nonadherence to prescribed therapy, or whitecoat effect. Pseudoresistance is commonly misdiagnosed as resistant hypertension. Careful assessment of pseudoresistance avoids overtreatment and expensive/excessive evaluation.

\section{Suboptimal treatment}

Suboptimal medical treatment is a major contributing factor to uncontrolled hypertension. Suboptimal treatment is frequently related to clinical inertia defined as the provider's failure to increase therapy when the treatment goal is not

\section{Key words}

Hypertension/therapy; blood pressure monitoring, ambulatory.

Mailing address: Eduardo Pimenta

933 19th Street South, Suíte 115 - Birmingham, AL 35294 - USA

E-mail: eduardopimenta@ccc.uab.edu

Manuscript received April 3, 2007; revised received April 3, 2007; accepted

April 10, 2007.

\begin{tabular}{l} 
Table 1 - Contributing factors for resistant hypertension \\
Volume expansion \\
Excess sodium intake \\
\hline Volume retention secondary to chronic kidney disease \\
\hline Inadequate diuretic therapy \\
Obesity \\
Exogenous substances \\
\hline Nonsteroidal anti-inflammatory agents \\
\hline Oral contraceptives \\
\hline Alcohol \\
Corticosteroids \\
\hline Anabolic steroids \\
Sympathomimetic agents (nasal decongestants, diet \\
pills, cocaine) \\
\hline Caffeine \\
\hline Cyclosporine \\
\hline Erythropoietin \\
\hline Chemotherapeutic agents \\
\hline Antidepressants \\
\hline
\end{tabular}

Table 2 - Secondary causes of hypertension

Hyperaldosteronism
Obstructive sleep apnea
Chronic kidney disease
Renal artery stenosis
Pheochromocytoma
Central nervous system tumors
Coarctation of the aorta
Thyroid diseases

reached. A retrospective study conducted in 7,253 hypertensive patients found that in patients with uncontrolled hypertension, providers had frequently failed to begin new medications or increase dosages of current medications during previous visits². Lack of knowledge of treatment guidelines, underestimation of cardiovascular (CV) risk, and the use of spurious reasons to avoid 
intensification of therapy, such as the physician's perception that the patient will not accept more medications, are related to clinicians failure to intensify treatment ${ }^{3,4}$.

\section{Nonadherence}

Poor adherence to prescribed medications is a common problem in patients with high blood pressure and a common cause of uncontrolled hypertension ${ }^{5}$. Poor adherence is common at the primary care level, but may be less common among patients who are seen by specialists ${ }^{6-8}$. Cost of treatment, poor relations between doctor and patient, multiple pills, and adverse effects of medical therapy are additional causes of poor adherence.

\section{White-coat effect}

White-coat effect, the difference between office BP and ambulatory (ABPM) or home BP measurements, can be calculated as the mean office BP minus mean daytime ambulatory BP. Mean daytime BP $<135 / 85 \mathrm{~mm} \mathrm{Hg}$ is considered normal for both ambulatory and home BP monitoring methods. The prevalence of significant white-coat effect ranges from 20 to $40 \%$ of all hypertensive patients and may be even more common in resistant hypertension. Whitecoat effect is more prevalent in women and older persons, and should be suspected in patients with symptoms related to hypotension in the absence of low BP recordings at the clinic and in those with high office BP without related target organ damage?.

Ambulatory and home BP monitoring are important methods to evaluate patients with uncontrolled $B P$ and rule out true treatment resistance in clinical practice. ABPM and home $B P$ measurements can avoid overtreatment and excessive visits to the clinic in patients with white-coat effect.

\section{Contributing factors}

\section{Volume expansion}

Volume expansion related to excessive dietary sodium, sodium retention secondary to CKD and/or failure to use diuretics appropriately can cause resistant hypertension ${ }^{10-12}$. Assessment of plasma volume status in patients with resistant hypertension may be useful in the selection and titration of more appropriate treatment, e.g. initiation or intensification of diuretic therapy in volume expanded patients; reninangiotensin-aldosterone system (RAAS) inhibitors/vasodilators in euvolemic vasoconstricted patients. Measurement of thoracic impedance can be useful in this regard ${ }^{13}$. A prospective study that randomized 104 patients with resistant hypertension to drug selection based on hemodynamic measurements or drug selection defined by a hypertension specialist found that patients randomized to treatment based on hemodynamic parameters had significantly higher control rates than patients whose treatment was based on specialist decision (56\% vs 33\%) ${ }^{14}$.

Diuretics are the cornerstone of treatment in patients whose BP cannot be controlled with multiple agents from other drug classes. Dietary salt reduction is a useful adjunctive treatment in patients with resistant hypertension, particularly because it enhances the potency of antihypertensive drugs ${ }^{1,15}$. Some demographic groups, including the elderly, the obese, African Americans and patients with CKD tended to be more saltsensitive and benefit more from dietary salt reduction.

\section{Obesity}

Obesity is common in patients with resistant hypertension. Data from the Framingham Heart Study showed that persons with a body mass index $(\mathrm{BMI}) \geq 30 \mathrm{~kg} / \mathrm{m}^{2}$ had a $50 \%$ higher probability of uncontrolled BP than patients with a normal BMI $\left(<25 \mathrm{~kg} / \mathrm{m}^{2}\right) .{ }^{16}$ Furthermore, the HYDRA study, a crosssectional study of 45,125 primary care patients, showed that those with a BMI $\geq 40 \mathrm{~kg} / \mathrm{m}^{2}$ had a higher prevalence of hypertension, as well as a 5.3 and 3.2 fold higher probability of requiring 4 or 3 antihypertensive drugs, respectively, to achieve BP control compared to patients with normal weight $\left(B M I \leq 25 \mathrm{~kg} / \mathrm{m}^{2}\right.$ ) (Figure 1) ${ }^{17}$. Increased sodium and fluid retention, sympathetic activation, and stimulation of the RAAS appear to contribute to high BP in obese subjects ${ }^{18}$.

\section{Exogenous substances}

Use of a variety of prescription drugs and other exogenous substances is commonly related to resistant hypertension (Table 1). A history of use of these agents should be queried in all patients with resistant hypertension. Withdrawal of these agents can reduce or even normalize BP in some patients with resistant hypertension.

Nonsteroidal anti-inflammatory drugs (NSAIDs), including selective cyclooxygenase (COX-) 2 inhibitors, are a common cause of uncontrolled BP and renal impairment in hypertensive patients ${ }^{19-21}$. NSAIDs appear to increase BP through volume and sodium retention, likely due to inhibition of vasodilating prostaglandins in the kidney. Elderly and diabetic patients are particularly susceptible to these adverse effects. The Nurses' Health Study prospectively analyzed the BP effect of non-narcotic analgesics in 51,630 normotensive female nurses 44 to 69 years of age followed for 8 years ${ }^{22+}$. Compared with nonusers, women who frequently used aspirin, acetaminophen or NSAIDs had a 21,20 , and $35 \%$ increased risk of developing hypertension, respectively. This study clearly demonstrated that aspirin and acetaminophen, as well as conventional NSAIDs, have important BP effects.

All NSAIDs appear to elevate mean BP and antagonize the BP lowering effects of antihypertensive drugs ${ }^{23}$. Selective COX-2 inhibitors are also associated with BP elevation. A meta-analysis of 45,451 patients enrolled in 19 randomized controlled trials showed that COX-2 inhibitors elevate BP by $\sim 4 / 1 \mathrm{~mm} \mathrm{Hg}$ compared to placebo, and by $\sim 3 / 1$ compared to NSAIDs ${ }^{24}$. The BP elevating effects of NSAIDs and COX-2 inhibitors are dose-related and some agents appear to have greater effects than others. For example, in the Multinational Etoricoxib and Diclofenac Arthritis Longterm (MEDAL) program which randomized 34,701 patients with osteoarthritis or rheumatoid arthritis to etoricoxib or diclofenac, patients assigned to etoricoxib discontinued the study due to hypertension more frequently than those assigned to diclofenac ${ }^{25}$. Of the selective COX-2 inhibitors, 


\section{Review Article}

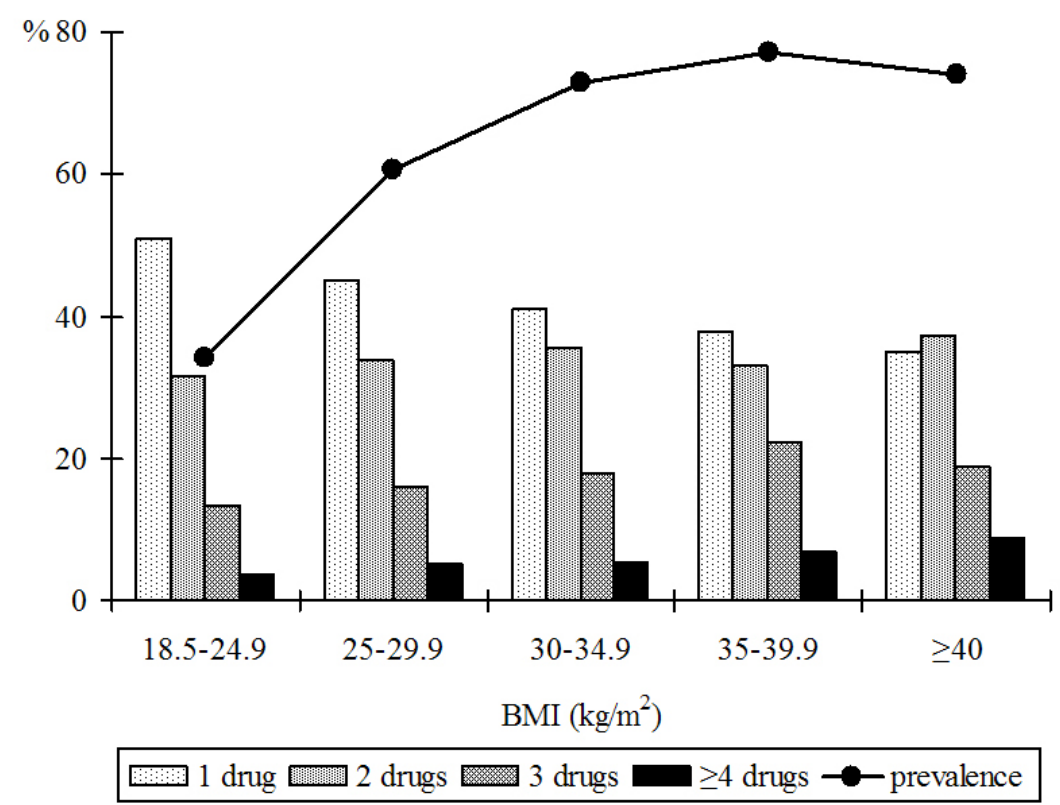

Fig. 1 - Increasing use of combination therapy and increase of prevalence of hypertension according to body mass index. Adapted from Bramlage P, et al. Am J Hypertens 2004; 17: 904-10.

rofecoxib is more likely to raise BP compared to celecoxib in both normotensive and hypertensive subjects ${ }^{26}$. If analgesics are necessary in hypertensive patients, medications such as tramadol or hydrocodone and nerve block are useful alternatives to NSAIDs or COX-s inhibitors. If NSAIDs or COX2 inhibitors are needed, minimal effective doses should be prescribed. Providers must ask all hypertensive patients about use of pain control medications in order to avoid this form of iatrogenic resistant hypertension.

Oral contraceptives induce small increases in BP in the entire population of users, with frank hypertension occurring in a small number and resistant hypertension in an even smaller number of subjects ${ }^{27,28}$. The Nurses' Health Study prospectively followed 68,297 normotensive premenopausal female nurses for development of hypertension over 4 years ${ }^{29}$. Current oral contraceptive users had an $80 \%$ increased risk of developing hypertension compared with never-users, but this increased risk resolved almost completely with withdrawal of the medication (Figure 2). Furthermore, oral contraceptive use in persons with underlying hypertension is associated with uncontrolled BP. A cross-sectional study evaluating the association between oral contraceptives and BP control in 171 hypertensive women found that oral contraceptive users had poorer BP control and tended to have more severe hypertension than users of other contraceptive methods or nonusers ${ }^{30}$. Combined (estrogen + progestin) oral contraceptives are more often associated with BP increases than progestin-only oral contraceptives. Progestins have mineralocorticoid receptor antagonist effects that may account for their BP neutral or BP lowering actions. The new $4^{\text {th }}$ generation progestin, drospirenone, when combined with estradiol, has been shown to reduce $\mathrm{BP}^{31}$. Based on these and other data, progestin-only contraceptives are recommended

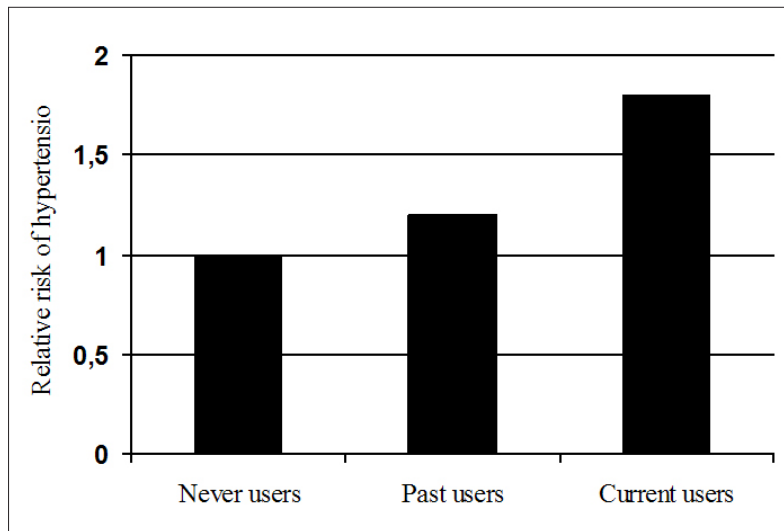

Fig. 2 - Relative risk for development of hypertension by current and past oral contraceptive users compared to never-users. Adapted from Chasan-Taber L, et al. Circulation 1996; 94: 483-9.

for women with established hypertension.

The World Health Organization ${ }^{32}$ and the American College of Obstetrics and Gynecology ${ }^{33}$ recommend use of combined oral contraceptives containing low doses of estrogen for women who are free of CV disease and major CV risk factors, including hypertension. Progestinonly contraceptives, including intrauterine devices are recommended for women with established CV disease, at high CV risk, migraine headaches with focal neurologic signs or history of thromboembolic disease.

Menopausal hormone therapy has minimal effects on BP and is not contraindicated in either normotensive or hypertensive women. Nevertheless, all hypertensive women treated with menopausal hormone therapy should have 
their BP measured initially and then at 3-6-month intervals depending on the difficulty of control ${ }^{34}$.

Heavy alcohol ingestion increases the risk of uncontrolled hypertension. In a cross sectional analysis, men with excessive alcohol intake ( $\geq 4$ glasses per day) had $50 \%$ higher probability of poor BP control ${ }^{35}$. Alcohol cessation promotes $\mathrm{BP}$ reduction and improves adherence to treatment. A prospective study of the effect of 1 month of abstinence on 24-hr BP in heavy drinkers documented an average reduction of $7.2 \mathrm{~mm} \mathrm{Hg}$ in 24-hr SBP and $6.6 \mathrm{~mm} \mathrm{Hg}$ in 24-hr diastolic BP (DBP). ${ }^{36}$ The prevalence of hypertension among study subjects decreased from $42 \%$ to $12 \%$. Moderation in alcohol consumption $(\leq 2$ drinks per day) is recommended as a lifestyle modification in the general population, especially in patients with hypertension, and complete cessation should be advised in the case of heavy drinkers.

Other exogenous substances that contribute to hypertension, such as corticosteroids, sympathomimetic agents, erythropoietin, and antidepressants should be avoided in patients with high BP and should be discontinued if at all possible in those with uncontrolled BP. In subjects to whom these substances are essential, more frequent BP evaluations and increased doses and/or numbers of antihypertensive medications may be required.

\section{Secondary hypertension}

The prevalence of secondary hypertension is greater in patients with resistant hypertension than in the general hypertensive population. The most common secondary causes of resistant hypertension are hyperaldosteronism, chronic kidney disease, renal artery stenosis and obstructive sleep apnea (Table 2). The prevalence of secondary hypertension increases with age, mainly due to increases in chronic kidney disease, obstructive sleep apnea, and renal artery stenosis.

\section{Hyperaldosteronism}

The aldosterone excess syndrome was initially described by Jerome Conn in 1955 in a patient with prolonged hypokalemia, severe hypertension and adrenal tumor ${ }^{37}$. However, the modern syndrome of hyperaldosteronism differs from classical primary aldosteronism. Hypokalemia and adrenal tumors are no longer required for the diagnosis of hyperaldosteronism. In fact, a substantial proportion of patients with hyperaldosteronism have normal potassium levels. In our experience $50 \%$ of patients with hyperaldosteronism and resistant hypertension have normal potassium levels or have never needed potassium supplementation ${ }^{38}$.

Hyperaldosteronism is now recognized as the most common cause of secondary hypertension and is a common contributor to treatment resistance ${ }^{39-45}$. Among untreated patients, hyperaldosteronism prevalence increases with increasing hypertension severity, from $2 \%$ in patients with stage 1 hypertension to $8 \%$ in those with stage 2 hypertension and $13 \%$ in those with stage 3 hypertension ${ }^{39}$. The prevalence of hyperaldosteronism is even higher in patients with resistant hypertension, approaching $17-22 \%$ in multiple studies ${ }^{46-49}$. In a prospective evaluation of patients referred to our own specialty clinic for resistant hypertension, defined as uncontrolled hypertension despite use of three or more medications, 18 of 88 (prevalence of 20\%) patients had hyperaldosteronism based on suppressed renin activity and high 24-hr urinary aldosterone excretion while consuming a high salt diet ${ }^{46}$.

Because of its high prevalence in this patient group, all patients with resistant hypertension, even those with normokalemia, should be evaluated for hyperaldosteronism. A presumptive diagnosis of aldosterone excess can be made by documenting elevated aldosterone levels in plasma and urine in the setting of suppressed renin activity. Measurement of plasma aldosterone concentration (PAC) level/plasma renin activity (PRA) ratio (ARR) has been shown to have sufficient sensitivity and specificity to serve as an effective screening test for hyperaldosteronism. Although the exact test characteristics of the ARR have varied widely between studies, its negative predictive value has been such that a low ARR $(<20$ when PAC is measured in $\mathrm{ng} / \mathrm{dl}$ and PRA is measured in $\mathrm{ng} / \mathrm{ml} / \mathrm{min}$ ) reliably excludes hyperaldosteronism. The specificity of ARR is less consistent insofar that a high ratio ( $>20-30)$ is suggestive, but not diagnostic of hyperaldosteronism. Accordingly, a high ARR is suspicious of hyperaldosteronism, but the diagnosis must be confirmed.

Demonstration of increased 24-hr urinary excretion of aldosterone confirms the diagnosis of hyperaldosteronism in patients with resistant hypertension ${ }^{50}$. As a first approach, PRA, 24-hr excretion of aldosterone and sodium can be measured in patients on their normal diets. (Measuring aldosterone and sodium from the same urine collection requires use of a non-salt preservative such as acetic acid). If the aldosterone excretion ( $\geq 12 \mu \mathrm{g} / 24-\mathrm{hr}$ ) and the sodium excretion are both high ( $\geq 200 \mathrm{mEq} / 24-\mathrm{hr}$ ), indicative of chronic high salt intake, it is not necessary to do additional salt loading to confirm hyperaldosteronism (Figure 3). If the aldosterone is high but the sodium is low ( $<200 \mathrm{mEq} / 24-\mathrm{hr})$ in the first collection, we repeat the collection after oral salt supplementation sufficient to increase the sodium $\geq 200 \mathrm{mEq} / 24$-hr.

After confirmation of biochemical hyperaldosteronism, thin-section abdominal CT imaging is recommended in an attempt to identify adrenal tumors. Even in the setting of confirmed biochemical hyperaldosteronism, CT imaging has a poor specificity for identifying adenoma and adrenal vein sampling can confirm or exclude lateralization of aldosterone excretion consistent with a unilateral adenoma. Laparoscopic adrenalectomy should be considered in patients with unilateral adenoma. For patients with contraindications to surgery or who do not have tumors, treatment with a mineralocorticoid receptor antagonist promotes $\mathrm{BP}$ reduction and regresses target organ damage.

\section{Obstructive sleep apnea}

Obstructive sleep apnea (OSA), characterized by preserved and increased respiratory effort despite partial or complete occlusion of the upper airway, is a common finding in patients with resistant hypertension ${ }^{51,52}$. OSA is strongly related to resistant hypertension and can predict hypertension in normotensive subjects ${ }^{53,54}$. A report of overnight polysomnographic studies in 41 unselected patients with resistant hypertension found OSA, defined as an apneahypopnea index of $\geq 10$ events/hour in $83 \%$ of patients ${ }^{55}$. The 


\section{Review Article}

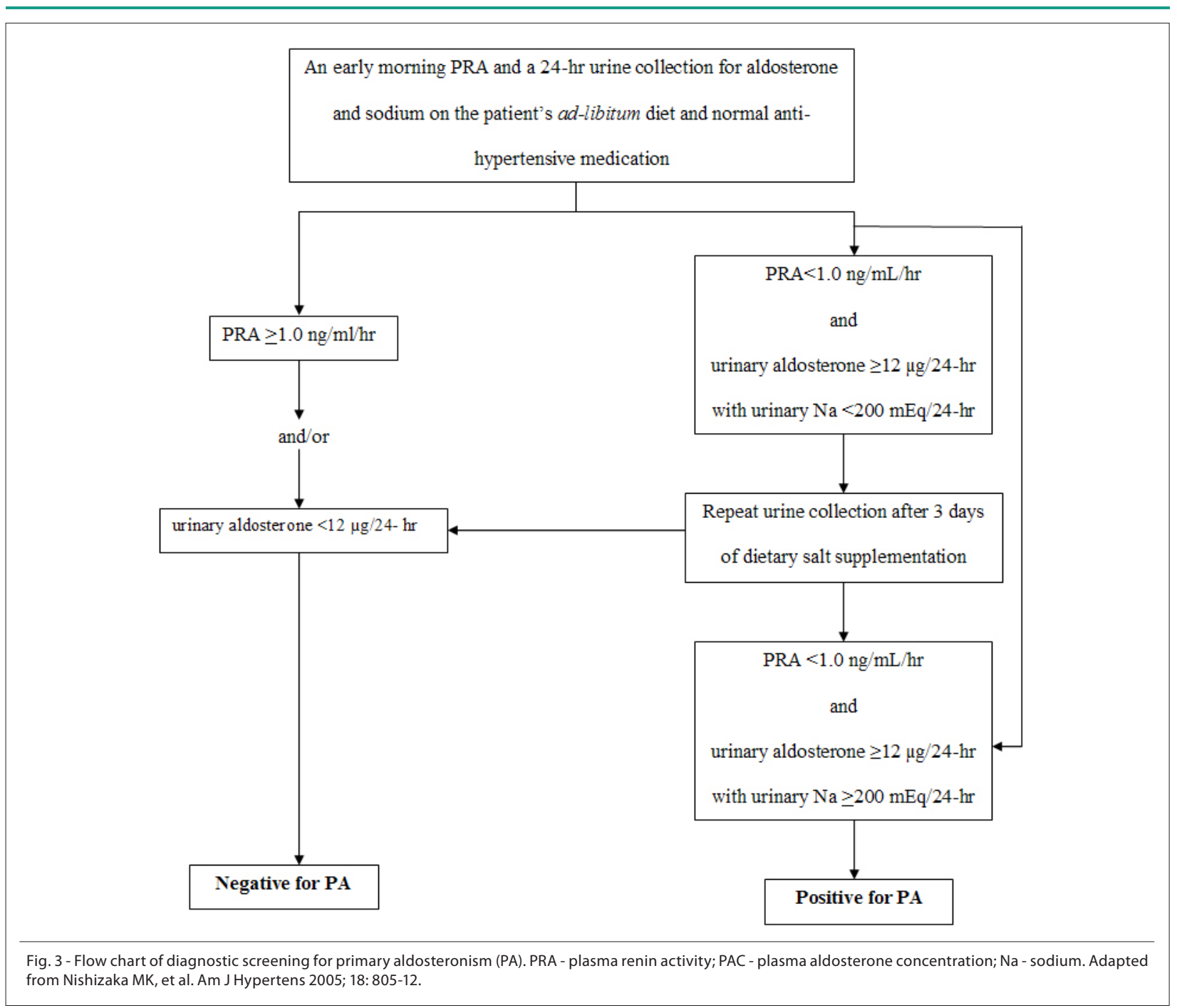

prevalence and severity were significantly higher in men than in women with resistant hypertension. Our clinic reported that $85 \%$ of patients with resistant hypertension have OSA defined as an apnea-hypopnea index of $\geq 5$ events/hour ${ }^{52}$.

There is an association between aldosterone excess, obesity and sleep apnea ${ }^{56,57}$. Stimulation of aldosterone release by visceral fat, excessive sodium retention stimulated by sympathetic activation and hypoxemia are possible mechanisms related to this association ${ }^{56}$. Sympathetic activity is increased in patients with hypertension and OSA, suggesting that intermittent hypoxemia could contribute to adrenergic activation ${ }^{58}$. Obesity and/or sleep-disordered breathing also may stimulate the adrenal gland to produce inappropriately large amounts of aldosterone. However, the mechanisms by which OSA could lead to hypertension are not completely elucidated (Figure 4).

Continuous positive airway pressure (CPAP) treatment is the gold standard for management of OSA. However, the role of CPAP in the treatment of hypertension is not well established. While cause and effect between OSA and resistant hypertension cannot be inferred, patients with resistant hypertension and OSA should be treated with CPAP and encouraged to lose weight. Oropharyngeal surgery has proved disappointing as a treatment for obstructive sleep apnea.

\section{Chronic kidney disease}

CKD is a common cause of resistant hypertension and a consequence of poor BP control over time. Fluid retention, excessive activation of the RAAS and concomitant medicines are related to treatment resistance in patients with impaired renal function (Figure 5$)^{59}$.

All patients with resistant hypertension should have their glomerular filtration rate estimated by use of the Modification of Diet in Renal Disease (MDRD) Study or Cockcroft-Gault equation ${ }^{60}$, since serum creatinine is an unreliable marker of CKD, particularly in elderly patients. Albuminuria should also be assessed. Dietary salt reduction plays an important role in order to decrease the volume expansion. Loop diuretics are indicated to effectively reduce volume and facilitate BP control in patients with creatinine clearance $<30 \mathrm{ml} / \mathrm{min}$. Angiotensin converting enzyme (ACE) inhibitors or angiotensin receptor blockers (ARBs) are indicated in patients with mild 


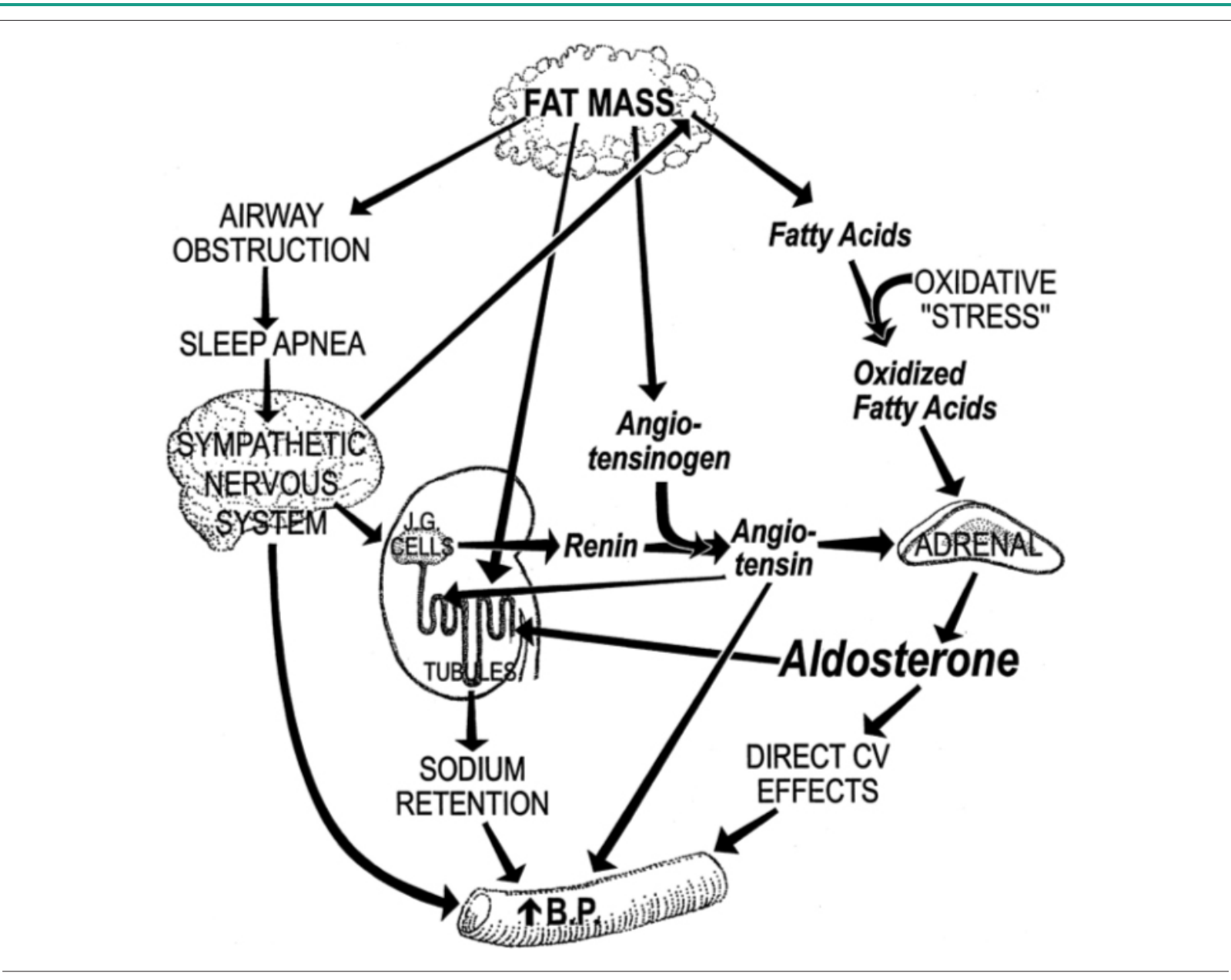

Fig. 4 - Real and theoretical links connecting obesity to hypertension. From Goodfriend TL and Calhoun DA. Hypertension. 2004 ; 43: 518-24.

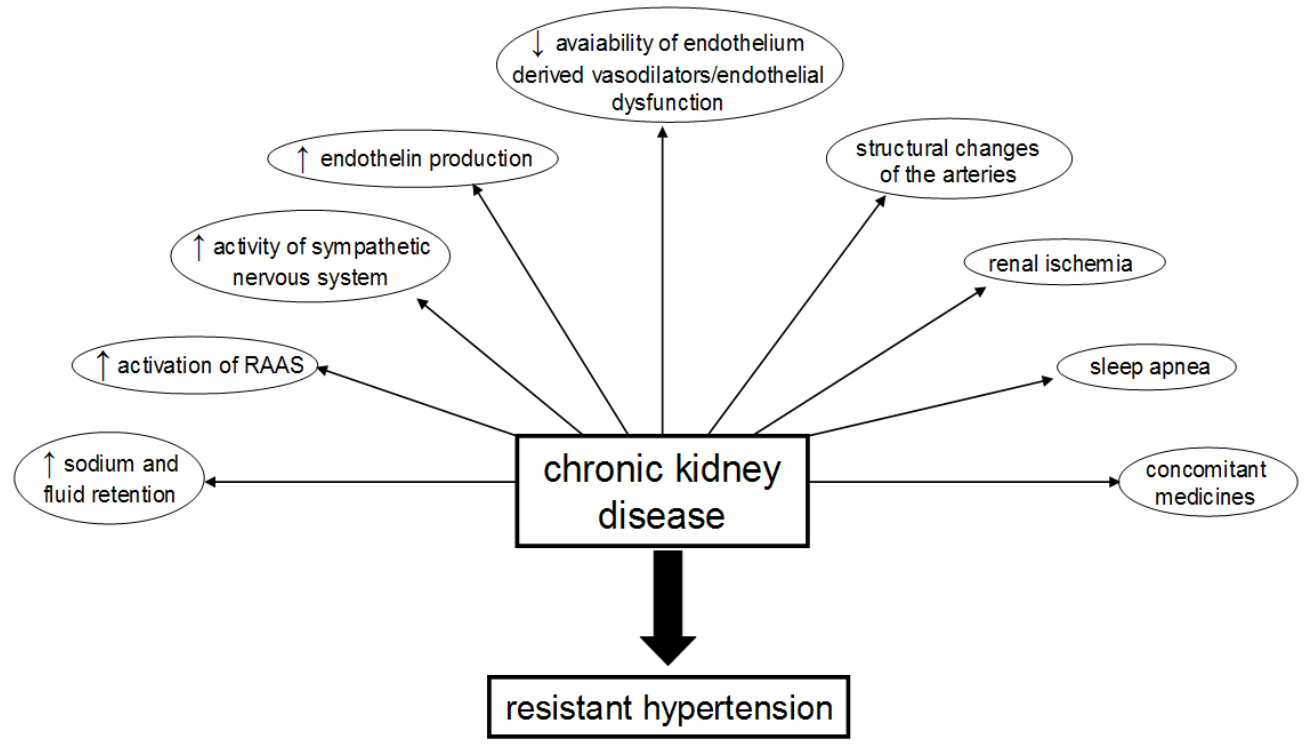

Fig. 5 - Factors linking chronic kidney disease and resistant hypertension. RAAS - renin-angiotensin system. 


\section{Review Article}

to severe CKD, particularly in the presence of micro- or macroalbuminuria. Blockade of the RAAS in patients with CKD reduces cardiovascular risk, improves $\mathrm{BP}$ control, and reduces proteinuria and progression to end stage renal disease ${ }^{61}$. Transitory and usually limited decreases in glomerular filtration rate can occur after instituting ACE inhibitors or ARBs and are not an indication for cessation of therapy.

\section{Renal artery stenosis}

Renovascular disease is a common finding in hypertensive patients with multiple risk factors and extra-renal atherosclerotic disease, particularly among patients with resistant hypertension ${ }^{62,63}$. Approximately $10 \%$ of cases of renal artery stenosis are attributable to fibromuscular dysplasia. Those patients are more likely to be women, to be younger than 50 years of age, and to be successfully treated with renal revascularization ${ }^{64}$

The vast majority (90\%) of renal artery lesions are atherosclerotic in etiology, and this prevalence increases with age ${ }^{65,66}$. Patients with resistant hypertension and known atherosclerotic disease, declining renal function, or a history of flash pulmonary edema have an increased likelihood of atherosclerotic renal arterial disease and should be evaluated with Doppler or magnetic resonance angiography of the renal arteries. The choice of treatment for atherosclerotic renal lesions is controversial due to a lack of strong evidence in favor of either medical treatment or revascularization for $\mathrm{BP}$ control and preservation of renal function ${ }^{67,68}$. CORAL is a large ongoing randomized clinical trial that is comparing the effects of optimal medical treatment alone to stent revascularization plus optimal medical treatment on a composite cardiovascular and renal end point in hypertensive patients with atherosclerotic renal artery stenosis ${ }^{69}$. Patients with resistant hypertension should be screened for renal artery stenosis and considered for revascularization if the anatomy of the lesion(s) is appropriate and if the BP cannot be controlled with optimal medical treatment. Stent therapy is superior to balloon angioplasty for atherosclerotic renal arterial lesions ${ }^{70}$.

\section{Pheochromocytoma}

The prevalence of pheochromocytoma in general hypertensive population is low $(0.1-0.6 \%)^{71,72}$, but diagnosis and treatment are extremely important due to difficult-to-control hypertension, the possibility of precipitating hypertensive crisis if the tumor is stimulated and the possibility that the tumor could be malignant. Headaches, palpitations, and sweating are the most common findings, but the clinical presentation of pheochromocytoma is widely variable ${ }^{73}$. Pheochromocytoma is associated with increased BP variability due to fluctuations in the levels of norepinephrine secreted by the tumor.

All patients with resistant hypertension and symptoms typical of pheochromocytoma should be screened. Pheochromocytoma should be ruled out in pregnant women with symptoms and signs of pheochromocytoma before 20 weeks gestation, because pheochromocytoma is related to increased maternal and fetal morbidity and mortality ${ }^{74}$. Plasma free metanephrine is the best screening test for pheochromocytoma, with high sensitivity (99\%) and specificity $(82 \%)^{73}$. Surgical removal is the appropriate treatment.

\section{Treatment of resistant hypertension}

Treatment of a patient with resistant hypertension includes removal of contributing factors, appropriate treatment of secondary causes and use of effective multi-drug regimens. Nonpharmacologic therapies, such as weight loss, exercise, dietary salt reduction, and moderation of alcohol intake should be encouraged in all patients. Interfering substances should be withdrawn or down-titrated as much as possible and obstructive sleep apnea should de treated.

Factors related to poor adherence need to be assessed. Discussing the cost and adverse effects of medications, number of pills, and objectives of treatment can improve patient adherence. Multidisciplinary teams, including nurses, pharmacists, nutritionists, psychology, and fitness trainers can improve treatment results ${ }^{75}$.

\section{Pharmacologic treatment}

Full doses of appropriate combinations such as an ACE or ARB, calcium channel blocker, and a thiazide diuretic are generally very effective and well tolerated. Patients with resistant hypertension often have occult volume retention and effective diuretic therapy is essential for BP control ${ }^{6,13}$. Long-acting thiazide diuretics are effective in most patients with resistant hypertension. Loop diuretics are preferable in patients with CKD if creatinine clearance is $<30 \mathrm{ml} /$ min. Furosemide is relatively short-acting and it should be prescribed at least twice-daily. Serum potassium needs to be monitored closely.

Mineralocorticoid receptor antagonists promote significant additional BP reduction independent of aldosterone/renin levels in patients with resistant hypertension (Figure 6) $38,76-78$. Our group has described the effect of low-dose (12.5 to $25 \mathrm{mg} /$ day) spironolactone in patients with uncontrolled BP on an average of four medications, including ACE inhibitor or $A R B$, and a diuretic ${ }^{38}$. After 6 months of follow-up SBP was reduced by 25 $\mathrm{mm} \mathrm{Hg}$ and DBP by $12 \mathrm{~mm} \mathrm{Hg}$. BP reductions were similar in patients with and without hyperaldosteronism, and the BP response to spironolactone was not predicted by baseline PAC or PRA or by 24-hr urinary aldosterone excretion. The benefit

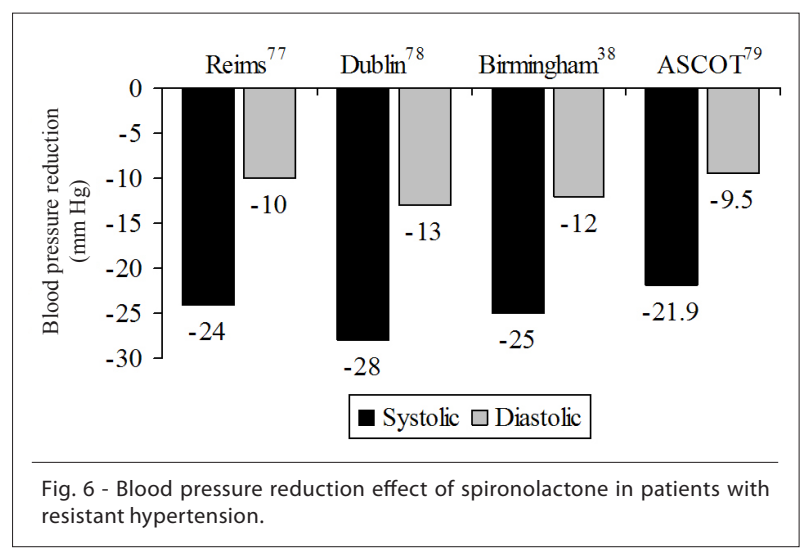


was similar in African-American and Caucasian subjects. Data from the Anglo-Scandinavian Cardiac Outcomes Trial-Blood Pressure Lowering Arm (ASCOT) also demonstrated a significant BP lowering effect of spironolactone as fourth-line therapy. SBP and DBP were reduced by 21.9 and $9.5 \mathrm{~mm} \mathrm{Hg}$, respectively, with spironolactone treatment in 1,411 participants ${ }^{78}$.

Spironolactone was generally well tolerated in these studies, although breast tenderness occurred in about $10 \%$ of the men. The more selective mineralocorticoid receptor antagonist eplerenone is better tolerated than spironolactone, with a lower incidence of breast tenderness, gynecomastia, sexual dysfunction, and menstrual irregularities, and has been shown to effectively reduce $\mathrm{BP}^{79}$.

Hyperkalemia, with or without acute renal insufficiency was uncommon in spite of concomitant using of an ACE inhibitor or ARB, but older patients and those with CKD or diabetes are at increased risk of developing hyperkalemia. Serum potassium and creatinine levels should be monitored in patients treated with mineralocorticoid receptor antagonists, particularly if they are receiving concomitant ACE inhibitor or ARB therapy. Potassium supplementation or salt substitutes that contain potassium should be discontinued or reduced in patients who are started on mineralocorticoid receptor antagonists.

\section{References}

1. Chobanian AV, Bakris GL, Black HR, Cushman WC, Green LA, Izzo JL Jr, et al. Seventh Report of the Joint National Committee on prevention, detection, evaluation, and treatment of high blood pressure. Hypertension. 2003; 42 1206-52.

2. Okonofua EC, Simpson KN, Jesri A, Rehman SU, Durkalski VL, Egan BM. Therapeutic inertia is an impediment to achieving the healthy people 2010 blood pressure control goals. Hypertension. 2006; 47:345-51.

3. Fine LJ, Cutler JA. Hypertension and the treating physician: understanding and reducing therapeutic inertia. Hypertension. 2006; 47:319-20.

4. Phillips LS, Branch WT Jr, Cook CB, Doyle JP, El-Kebbi IM, Galina DL, et al. Clinical inertia. Ann Intern Med. 2001; 135: 825-43.

5. Osterberg L, Blaschke T. Adherence to medication. N Engl J Med. 2005; 353: 487-97.

6. Garg JP, Elliott WJ, Folker A, Izhar M, Black HR, for the RUSH Unity Hypertension Service. Resistant hypertension revisited: a comparison of two university-based cohorts. Am J Hypertens. 2005; 18:619-26.

7. Bansal N, Tendler BE, White WB, Mansoor GA. Blood pressure control in the hypertension clinic. Am J Hypertens. 2003; 16: 878-80.

8. Mancia G, Pessina AC, Trimarco B, Grassi G, for the SILVIA Study Group. Blood pressure control according to new guidelines targets in low- to highrisk hypertensives managed in specialist practice. J Hypertens. 2004; 22 2387-96.

9. Muxfeldt ES, Bloch KV, Nogueira AR, Salles GF. Twenty-four hour ambulatory blood pressure monitoring pattern of resistant hypertension. Blood Press Monit. 2003; 8: 181-5.

10. Dustan HP, Tarazi RC, Bravo EL. Dependence of arterial pressure on intravascular volume in treated hypertensive patients. N Engl J Med. 1972; 286: 861-6.

11. Finnerty FA Jr, Davidov M, Mroczek WJ, Gavrilovich L. Influence of extracellular fluid volume on response to antihypertensive drugs. Circ Res.

\section{Conclusion}

Resistant hypertension defined as uncontrolled BP despite use of at least 3 antihypertensive medications is an increasingly common problem. Hyperaldosteronism obesity, volume expansion, and OSA are common findings in patients with resistant hypertension. Mineralocorticoid receptor antagonists are an effective therapeutic option for treatment of resistant hypertension even in the absence of demonstrable aldosterone excess.

\section{Potential conflict of interest}

Disclosures: Dr. Pimenta has no conflicts. Dr. Calhoun has served as a consultant for Novartis; has received grant support from Novartis, Merck, Astra-Zeneca and Encysive Pharmaceuticals. Dr. Oparil has received grantsin-aid from Abbott Laboratories, Astra-Zeneca, Aventis, Biovail, Boehringer Ingelheim, Bristol Myers-Squibb, Forest Laboratories, GlaxoSmithKline, Novartis, Merck \& Co, Pfizer, Sankyo Pharma, Sanofi-Synthelabo, Schering-Plough; has served as consultant for Bristol Myers-Squibb, Daiichi Sankyo, Merck \& Co, Novartis, Pfizer, Sanofi Aventis, and The Salt Institute, and is a member of Board of Directors for Encysive Pharmaceuticals.

12. Haddy FJ. Role of dietary salt in hypertension. Life Sci. 2006; 79: 1585-92.

13. Ventura HO, Taler SJ, Strobeck JE. Hypertension as a hemodynamic disease: the role of impedance cardiography in diagnostic, prognostic, and therapeutic decision making. Am J Hypertens. 2005; 18: 26-43S.

14. Taler SJ, Textor SC, Augustine JE. Resistant hypertension: comparing hemodynamic management to specialist care. Hypertension. 2002; 39 982-8.

15. He FJ, MacGregor GA. Effect of longer-term modest salt reduction on blood pressure. Cochrane Database Syst Rev. 2004. DOI:10.1002/14651858. CD004937.

16. Lloyd-Jones DM, Evans JC, Larson MG, O'Donnell CJ, Roccella EJ, Levy D. Differential control of systolic and diastolic blood pressure: factors associated with lack of blood pressure control in the community. Hypertension. 2000 36: 594-9.

17. Bramlage $P$, Pittrow D, Wittchen HU, Kirch W, Boehler S, Lehnert H, et al. Hypertension in overweight and obese primary care patients is highly prevalent and poorly controlled. Am J Hypertens. 2004; 17: 904-10.

18. Hall JE. The kidney, hypertension, and obesity. Hypertension. 2003; 41: 625-33.

19. Wilson SL, Poulter NR. The effect of non-steroidal anti-inflammatory drugs and other commonly used non-narcotic analgesics on blood pressure level in adults. J Hypertens. 2006; 24: 1457-69.

20. Gaziano JM. Nonnarcotic analgesics and hypertension. Am J Cardiol. 2006; 97: 10-6E.

21. Whelton A. Renal and related cardiovascular effects of conventional and and COX-2-specific NSAIDs and non-NSAID analgesics. Am J Ther. 2000; 7 : 63-74.

22. Dedier J, Stampfer MJ, Hankinson SE, Willett WC, Speizer FE, Curhan 


\section{Review Article}

GC. Nonnarcotic analgesic use and the risk of hypertension in US women. Hypertension. 2002; 40:604-8.

23. Johnson AG, NguyenTV, Day RO. Do nonsteroidal anti-inflammatory drugs affect blood pressure? A meta-analysis. Ann Intern Med. 1994; 121:289-300.

24. AwTJ, Haas SJ, Liew D, Krum H. Meta-analysis of cyclooxygenase-2 inhibitors and their effects on blood pressure. Arch Intern Med. 2005; 165: 490-6.

25. Cannon CP, Curtis SP, FitzGerald GA, Krum H, Kaur A, Bolognese JA, et al. Cardiovascular outcomes with etoricoxib and diclofenac in patients with osteoarthritis and rheumatoid arthritis in the Multinational Etoricoxib and Diclofenac Arthritis Long-term (MEDAL) programme: a randomised comparison. Lancet. 2006;368: 1771-81.

26. Wolfe F, Zhao S, Reynolds M, Pettitt D. Blood pressure destabilization and edema among 8538 users of celecoxib, rofecoxib, and nonselective nonsteroidal antiinflammatory drugs (NSAID) and nonusers of NSAID receiving ordinary clinical care. J Rheumatol. 2004; 31:1143-51.

27. Prentice RL. On the ability of blood pressure effects to explain the relation between oral contraceptives and cardiovascular disease. Am J Epidemiol. 1988; 127:213-9.

28. Rosenthal T, Oparil S. Oral contraceptives, hormones replacement therapy, and hypertension. In: Lip G, Hall J eds. Comprehensive hypertension. New York: Elsevier/Mosby. 2007.In press.

29. Chasan-Taber L, Willett WC, Manson JE, Spiegelman D, Hunter DJ, Curhan $\mathrm{G}$, et al. Prospective study of oral contraceptives and hypertension among women in the United States. Circulation. 1996; 94:483-9.

30. Lubianca JN, Faccin CS, Fuchs FD. Oral contraceptives: a risk factor for uncontrolled blood pressure among hypertensive women. Contraception. 2003; 67: 19-24.

31. White WB, Hanes V, Chauhan V, Pitt B. Effects of a new hormone therapy, drospirenone and $17 \beta$-estradiol, in postmenopausal women with hypertension. Hypertension. 2006; 48: 246-53.

32. World Health Organization. Low dose combined oral contraceptives In: Improving access to quality care in family planning: medical eligibility criteria for contraceptive use. 3rd ed. Geneva, Switzerland: World Health Organization, 2004

33. American College of Obstetricians and Gynecologists Practice Bulletin. Use of hormonal contraception in women with coexisting medical conditions: clinical management guidelines for obstetrician-gynecologists. Obstet Gynecol. 2006; 107: 1453-72.

34. Pimenta E, Oparil S. Gender and blood pressure. In: Izzo JL Jr, Sica D, Black HR (eds). Hypertension primer. 4th ed. Baltimore: Lippincott, Williams \& Wilkins. 2007. In press.

35. de Gaudemaris R, Lang T, Chatellier G, Larabi L, Lauwers-Cances V, Maitre $A$, et al. Socioeconomic inequalities in hypertension prevalence and care. The IHPAF Study. Hypertension. 2002; 39: 1119-25.

36. Aguilera MT, de la Sierra A, Coca A, Estruch R, Fernandez-Sola J, Urbano-Marquez A. Effect of alcohol abstinence on blood pressure: assessment by 24-hou ambulatory blood pressure monitoring. Hypertension. 1999;33:653-7.

37. Conn JW. Presidential address. I. Painting background. II. Primary aldosteronism, a new clinical syndrome. J Lab Clin Med. 1955; 45: 3-17.

38. Nishizaka MK, Zaman MA, Calhoun DA. Efficacy of low-dose spironolactone in subjects with resistant hypertension. Am J Hypertens. 2003; 16: 925-30.

39. Mosso L, Carvajal C, Gonzalez A, Barraza A, Avila F, Montero J, et al. Primary aldosteronism and hypertensive disease. Hypertension. 2003;42: 161-5.

40. Rayner BL, Opie LH, Davidson JS. The aldosterone/renin ratio as a screening test for primary aldosteronism. S Afr Med J. 2000; 90: 394-400.

41. Fardella CE, Mosso L, Gomez-Sanchez C, Cortes P, Soto J, Gomez L, et al. Primary hyperaldosteronism in essential hypertensives: prevalence, biochemical profile, and molecular biology. J Clin Endocrinol Metab. 2000; 85: $1863-7$.

42. Lim PO, Dow E, Brennan G, Jung RT, MacDonald TM. High prevalence of primary aldosteronism in the Tayside hypertension clinic population. J Hum Hypertens. 2000; 14:311-5.

43. Rayner BL, Myers JE, Opie LH, Trinder YA, Davidson JS. Screening for primary aldosteronism-normal ranges for aldosterone and renin in three South African population groups. S Afr Med. J 2001; 91: 594-9.

44. Lim PO, Rodgers P, Cardale K, Watson AD, MacDonald TM. Potentially high prevalence of primary aldosteronism in a primary-care population. Lancet. $1999 ; 353: 40$

45. Loh KC, Koay ES, Khaw MC, Emmanuel SC, Young WF Jr. Prevalence of primary aldosteronism among Asian hypertensive patients in Singapore. J Clin Endocrinol Metab. 2000; 85: 2854-9.

46. Calhoun DA, Nishizaka MK, Zaman MA, Thakkar RB, Weissmann P. Hyperaldosteronism among black and white subjects with resistant hypertension. Hypertension. 2002; 40: 892-6.

47. Gallay BJ, Ahmad S, Xu L, Toivola B, Davidson RC. Screening for primary aldosteronism without discontinuing hypertensive medications: plasma aldosterone-renin ratio. Am J Kidney Dis. 2001; 37: 699-705.

48. Eide IK, Torjesen PA, Drolsum A, Babovic A, LilledahI NP. Low-renin status in therapy-resistant hypertension: a clue to efficient treatment. J Hypertens. 2004; $22: 2217-26$

49. Strauch B, Zelinka T, Hampf M, Bernhardt R, Widimsky J Jr. Prevalence of primary hyperaldosteronism in moderate to severe hypertension in the Central Europe region. J Hum Hypertens. 2003; 17:349-52.

50. Mattsson C, Young WF Jr. Primary aldosteronism: diagnostic and treatment strategies. Nat Clin Pract Nephrol. 2006; 2:198-208.

51. Martinez-Garcia MA, Gomez-Aldaravi R, Gil-Martinez T, Soler-Cataluna JJ, Bernacer-Alpera B, Roman-Sanchez P. Sleep-disordered breathing in patients with difficult-to-control hypertension. Arch Bronconeumol. 2006;42: 14-20.

52. Pratt-Ubunama MN, Nishizaka MK, Boedefeld RL, Cofield SS, Harding SM, Calhoun DA. Plasma aldosterone is related to severity of obstructive sleep apnea in subjects with resistant hypertension. Chest. 2007; 131:453-9.

53. Nieto FJ, Young TB, Lind BK, Shahar E, Samet JM, Redline S, et al. Association of sleep-disordered breathing, sleep apnea, and hypertension in a large community-based study. JAMA. 2000; 283: 1829-36.

54. Peppard PE, Young T, Palta M, Skatrud J. Prospective study of the association between sleep-disordered breathing and hypertension. N Engl J Med. 2000; 342: 1378-84

55. Logan AG, Perlikowski SM, Mente A, Tisler A, Tkacova R, Niroumand M, et al. High prevalence of unrecognized sleep apnoea in drug-resistant hypertension. J Hypertens. 2001; 19: 2271-7.

56. Goodfriend TL, Calhoun DA. Resistant hypertension, obesity, sleep apnea, and aldosterone: theory and therapy. Hypertension. 2004; 43:518-24.

57. Calhoun DA, Nishizaka MK, Zaman MA, Harding SM. Aldosterone excretion among subjects with resistant hypertension and symptoms of sleep apnea. Chest. 2004; 125: 112-7.

58. Grassi GG, Facchini A, Trevano FQ, Dell'Oro R, Arenare F, Tana F, et al. Obstructive sleep apnea-dependent and-independent adrenergic activation of obesity. Hypertension. 2005; 46: 321-5.

59. Campese VM, Mitra N, Sandee D. Hypertension in renal parenchymal disease: why is it so resistant to treatment? Kidney Int. 2006; 69: 967-73.

60. Levey AS, Coresh J, Balk E, Kausz AT, Levin A, Steffes MW, et al. National Kidney Foundation practice guidelines for chronic kidney disease: evaluation, classification, and stratification. Ann Intern Med. 2003; 139: 137-47.

61. Casas JP, Chua W, Loukogeorgakis S, Vallance P, Smeeth L, Hingorani AD, et al . Effect of inhibitors of the renin-angiotensin system and other antihypertensive drugs on renal outcomes: systematic review and meta-analysis. Lancet. 2005; 366: 2026-33.

62. Aqel RA, Zoghbi GJ, Baldwin SA, Auda WS, Calhoun DA, Coffey CS, et al. Prevalence of renal artery stenosis in high-risk veterans referred to cardiac catheterization. J Hypertens. 2003; 21: 1157-62.

63. Tumelero RT, Duda NT, Tognon AP, Thiesen M. Prevalence of renal artery stenosis in 1,656 patients who have undergone cardiac catheterization. Arq Bras Cardiol. 2006; 87: 248-53.

64. Birrer M, Do DD, Mahler F, Triller J, Baumgartner I. Treatment of renal artery Fibromuscular displasia with balloon angioplasty: a prospective follow-up study. Eur JVasc Endovasc Surg. 2002; 23: 146-52. 
65. Safian RD, Textor SC. Renal-artery stenosis. N Engl J Med. 2001;344:43142.

66. White, CJ. Catheter-based therapy for atherosclerotic renal artery stenosis. Circulation. 2006; 113: 1464-73.

67. Textor SC. Progressive hypertension in a patient with"incidental"renal artery stenosis. Hypertension. 2002; 40: 595-600.

68. GarovicVD, Textor SC. Renovascular hypertension and ischemic nephropathy. Circulation. 2005; 112: 1362-74.

69. Cooper CJ, Murphy TP, Matsumoto A, Steffes M, Cohen DJ, Jaff M, et al. Stent revascularization for the prevention of cardiovascular and renal events among patients with renal artery stenosis and systolic hypertension: rationale and design of the CORAL trial. Am Heart J. 2006; 152: 59-66.

70. White CJ. Catheter-based therapy for atherosclerotic renal artery stenosis. Circulation. 2006; 13: 1464-73.

71. Omura M, Saito J, Yamaguchi K, Kakuta Y, Nishikawa T. Prospective study on the prevalence of secondary hypertension among hypertensive patients visiting a general medicine outpatient clinic in Japan. Hypertens Res. 2004 27: 193-202.

72. Sinclair AM, Isles CG, Brown I, Cameron H, Murray GD, Robertson JW. Secondary hypertension in a blood pressure clinic. Arch Intern Med. 1987
147: 1289-93.

73. Lenders JW, Eisenhofer G, Manelli M, Pacak K. Pheochromocytoma. Lancet. 2005; 366: 665-75.

74. Grodski S, Jung C, Kertes P, Davies M, Banting S. Phaeochromocytoma in pregnancy. Intern Med J. 2006; 36: 604-6.

75. Goessens BM, Visseren FL, Olijhoek JK, Eikelboom BC, van der Graaf Y. Multidisciplinary vascular screening program modestly improves treatment of vascular risk factors. Cardiovasc Drugs Ther. 2005; 19:429-35.

76. Ouzan J, Perault C, Lincoff AM, Carre E, Mertes M. The role of spironolactone in the treatment of patients with refractory hypertension. Am J Hypertens. 2002; 15:333-9.

77. Mahmud A, Mahgoub M, Hall M, Feely J. Does aldosterone-to-renin ratio predict the anti-hypertensive effect of the aldosterone antagonist spironolactone? Am J Hypertens. 2005; 18: 1631-5.

78. Chapman N, Dobson J, Wilson S, Dahlof B, Sever PS, Wedel H, et al. Effect of spironolactone on blood pressure in subjects with resistant hypertension. Hypertension. 2007; 49: 839-45.

79. Flack JM, Oparil S, Pratt JH, Roniker B, Garthwaite S, Kleiman JH, et al. Efficacy and tolerability of eplerenone and losartan in hypertensive black and white patients. J Am Coll Cardiol. 2003; 41:1148-55. 